\title{
Empirical Study on the Relationship between ICT Application and China Agriculture Economic Growth
}

\author{
Pengju He, Shihong Liu, Huoguo Zheng, and Yunpeng Cui
}

Key Laboratory of Digital Agricultural Early-warning Technology Ministry of Agriculture, People's Republic of China, Beijing 100081, P.R. China

\begin{abstract}
In recent years, Chinese government attaches great importance to information and communication technology (ICT) application in agriculture. Driven by market profits and financial privilege, information and communication enterprises, agricultural enterprises, research institutes, universities and relative associations have actively involved in ICT application in agriculture for many years. Therefore, study on relationship between ICT application and China agriculture economic growth is of significance. This paper established a new model on agriculture economic growth and using panel data made an empirical study on the relationship between ICT application and china's agriculture economic growth.
\end{abstract}

Keywords: information and communication technology application; agriculture; economic growth; panel data; regression.

\section{Introduction}

Although there are few research results on the relationship between ICT application and agriculture economic growth, scholars have achieved some important results on the relationship between ICT application and economic growth, the methodology of which is also applicable. Studies on the relationship between ICT application and economic growth followed two directions. The first direction is from the perspective of industrial economics. Representative studies include: Marc U, Porat (1997) divides information sector into primary information sector and secondary information sector, using input-output table method, he measures the size of the U.S. information economy [1]. The second direction is from the perspective of production function, which deems ICT application as an economic input factor. Representative studies include: Gurmukh Gill, etc (1997) collects data in 11 cross-industry areas from 1983 to 1993 of 58 industries of United States and uses production function analyzing the contribution of information technology [2]. International Telecommunication Union in 2006 published "World Telecommunication/ICT Development Report" (2006) which demonstrates the information and communication technologies can greatly improve productivity and made an conclusion that the true potential of information and communication technology is not its direct impact on the economy, but the indirect impact on the whole economic system [3]. Welfens (2002) decomposed scientific and technological 
advances into information technology advances and non-information technology advances [4]. Formula 1 shows the relationship between technological progress, information technological progress and non-information technological progress:

$$
\mathrm{A}=\mathrm{A}_{0} \mathrm{Z}^{\gamma}
$$

In formula $1, \mathrm{Z}$ stands for the level of information technology advances. $\gamma$ stands for the output elasticity of information technology advances. $A_{0}$ stands for the advances of non-information technology.

In china, researches on the relationship between ICT application and economic growth are also followed the two directions, noteworthy studies includes: Zhu Youping (1996) uses C-D production, in which the dependent variable is China's real GDP and the independent variables are physical capital, labor force and informatization factor, collecting data from 1980 to 1992 to do regression analysis and finds out that the informatization factor makes the largest contribution of china's economic growth [5]. Tao Changqi (2001) does correlation analysis among information technology and equipment manufacturing, information services and traditional industry and finds out that correlation coefficient is of significant [6].

Researches on the relationship between ICT application and agriculture economic growth are comparatively few. Noteworthy studies include: Zhang Hong, Zhang Quan (2006) firstly uses the method of "information technology index in Japan" to measure China's rural information and then construct a model which seems rural informatization as a new factor. Further more, they conduct an empirical study on Chinese agricultural development from 1993 to 2002 and find out rural informatization plays an important role in china's agricultural development [7].

Although these studies mentioned above are useful, we can find out that there are still some limitations: firstly, most index system for measurement of ICT is not suitable in china, because some important indicators are not covered in china's statistics. Secondly, there are huge differences of ICT application level in different regions of china, most studies taking china as a whole without hypothesis testing to find out the relationship between ICT application and agriculture economic growth is inaccurate. This paper measures ICT application level in a different way, in which consumption and investment on ICT application is used as indicators of ICT application level. Then, this paper collects data in 30 provinces of china and using panel data analyzes the relationship between ICT application and agriculture economic growth.

This paper is organized as follows: Firstly, this paper makes a literature review on the relationship between ICT application and economic growth and put forward the research outline of this paper. Secondly, based on system engineering and information economic analysis, this paper established a new model, which sees ICT application as a new factor, on agriculture economic growth and makes an interpretation about the variables. Thirdly, using panel data from 1999 to 2006 in 30 provinces, this paper made an empirical study on the relationship between ICT application and china's agriculture economic growth. At last, this paper puts forward some suggestions on ICT application in china's agriculture. 


\section{Model and Variables Selection}

\subsection{Model Construction}

Based on the research results mentioned before, the agriculture economic growth model of this paper is built on three hypotheses. First, ICT application is a new independent factor of agricultural economic system; second, ICT application has a positive externality on agriculture economic growth; third, ICT application factor is an endogenous variable of agricultural economic system. Based on these three hypotheses, the form of agriculture production function can be expressed as follows:

$$
\mathrm{Y}=\mathrm{F} \quad\left(\mathrm{A}_{0}, \mathrm{~K}, \mathrm{H}, \mathrm{I}\right)
$$

In the model, $\mathrm{Y}$ stands for the total agriculture economy output, $\mathrm{A}_{0}$ stands for scientific and technological progress removing elements of the agricultural and rural information, $\mathrm{K}$ stands for physical capital investment, $\mathrm{H}$ stands for human capital investment, I stands for ICT application.

For the specific form of production function, this study uses Cobb - Douglas form. Put the time variable into the model, the model used in this study is showed as follows:

$$
Y_{t}=A_{0} K_{t}^{\alpha} H_{t}^{\beta} I_{t}^{\gamma}
$$

After necessary mathematical treatments of model 3, model 4 deduced from Model 3 is the statistical model to use:

$$
Y_{i t}{ }^{\prime}=C+\alpha K_{i t}{ }^{\prime}+\beta H_{i t}{ }^{\prime}+\gamma I_{i t}{ }^{\prime}+\sum_{i} \mu_{i} y_{i}+\xi_{i t}
$$

\subsection{Variables Selection and Data Procession}

Dependent variable $\mathrm{Y}$ : In this study, the total agricultural production was used to measure the output of the agricultural economy. The data can be collected from the item "primary industry of gross domestic product" (GDP) of "China Statistical Yearbook". In order to eliminate the impact of price factor, with 1990 prices as base year, "the first industrial GDP index" of "China Statistical Yearbook" was used to adjust the nominal value of primary industry of gross domestic product into actual values.

Physical capital K: In this study, the stock coming from fixed assets investments on the primary industry was used as a measure of agricultural physical capital. As there is no direct statistical data on agricultural physical capital stock in the country, this study as a common way used the perpetual inventory method to calculate it, the formula is: $\mathrm{K}_{t}=(1-\delta) \mathrm{K}_{t-1}+\mathrm{I}_{t}$. In the formula, $\mathrm{K}_{t}$ and $\mathrm{I}_{t}$ stand for the capital stock and new investment in $\mathrm{t}$ year respectively, $\delta$ stands for the depreciation rate. According to some research results, $\delta$ is assumed to be $5 \%$. For agricultural investment, $I_{t}$ can be collected from the fixed asset investment data on agriculture, forestry, animal husbandry and fishery of "China Rural Statistical Yearbook". This study uses the methods developed by Hall and Jones (1999) and Young (2000) to calculate the base period capital stock, 
the formula is: $\mathrm{K}_{0}=\mathrm{I}_{0} /(\mathrm{g}+\delta)$, in which, $\mathrm{I}_{0}$ stands for the investment of the base period, $\mathrm{g}$ stands for the annual average growth rate for investment. In order to eliminate the impact of price factor, this study, with the prices of 1990 the base year, used the investment index of each region to adjust the nominal value into actual value.

Human capital H: As this study uses the human capital indicators, rather than the labor force, thus it needs to translate different types of labor force into human capital stock. The method of is give different human capital equivalent coefficients to people of different educational levels. The human capital equivalent coefficients used in this study are coming from research results by Zhou Xiao, Zhu Nong (2003) [8]. Human Capital equivalent coefficients of all levels of education are shown in Table 1.

Table 1. Human Capital Coefficients

\begin{tabular}{crrccc}
\hline Illiteracy & $\begin{array}{c}\text { Primary } \\
\text { school }\end{array}$ & $\begin{array}{c}\text { Junior } \\
\text { school }\end{array}$ & $\begin{array}{c}\text { High } \\
\text { school }\end{array}$ & $\begin{array}{c}\text { Secondary } \\
\text { school }\end{array}$ & $\begin{array}{c}\text { College school } \\
\text { and above }\end{array}$ \\
\hline 1 & 1.07 & 1.254 & 1.1308 & $1.45^{*}$ & 1.624 \\
\hline
\end{tabular}

ICT application factor I: ICT application factor can be measured by the sum of consumption and investment on ICT application, which are more direct and accurate. The investment data on ICT application comes from three items, which are investments on "Information transmission, computer services and software", "Education" and a part of "Culture, Sports and Entertainment" in "China Rural Statistical Yearbook". The consumption data on ICT application comes from two items, which are investments on communication expenses from "Transport and communication expenses" and "Cultural and entertainment products and services expenditure". In order to determine the percentage of the investment on "Culture, Sports and Entertainment" and the consumption on "Transport and communication expenses", this study conducted surveys in 30 provinces and made estimates on the partial. In order to eliminate the price factor, the data of investment on ICT application and the data of consumption on ICT application were adjusted by "investment index" and "consumption index". As the same, this study adopted the perpetual inventory method to calculate the ICT fixed asset stock in each province.

\section{Empirical Study and Results}

In order to analyze the impact of ICT application on agriculture economic growth, this paper made a comparative study. Model 5, which is a classical economic growth model, does not include ICT application factor, while model 6, which is constructed in part 2, includes ICT application factor. Model 5 and Model 6 are shown as follows:

$$
Y_{i t}{ }^{\prime}=C+\alpha K_{i t}{ }^{\prime}+\beta H_{i t}{ }^{\prime}+\sum_{i} \mu_{i} y_{i}+\xi_{i t}
$$




$$
Y_{i t}{ }^{\prime}=C+\alpha K_{i t}{ }^{\prime}+\beta H_{i t}{ }^{\prime}+\gamma I_{i t}{ }^{\prime}+\sum_{i} \mu_{i} y_{i}+\xi_{i t}
$$

For model 5, the dependent variable is the real GDP of agriculture department. Through correlation analysis, it can be found that these three independent variables including the stock of physical capital, human capital stock, ICT application factor and regional dummy variable exists strong autocorrelation, therefore, the regional dummy variable was excluded. Model 6, with the same reason, also excluded the regional dummy variable. Because the impact of ICT application lags behind the investment and consumption, so ICT application variable data lag a year in both model 5 and model 6 . Using the data in 30 provinces of China form 1999 to 2006, this paper conducts an empirical study on China's agricultural economic growth. Through the F test and Hausman test, both models should use time fixed effects, common cross-section coefficients model to do regression analysis. It should be note that cross-section weighting was used both in model 5 and model 6 . In this paper, the software which is used is Eviews5.0. Regression results of model 5 and Model 6 were shown in Table 2, 3.

In model 5, the R-square, Adjusted R-square are 0.999746, 0.999736 respectively. F-statistic value is 100678.4 and the Probability of F-statistic value is 0.000000 . Durbin-Watson statistic value is 0.54 . The elastic coefficients of physical capital, human capital element are $0.49,0.46$ and the sum of them is 0.95 approximately equal to 1 , indicating that for each additional unit of regional physical capital, human capital input can stimulate agricultural growth $0.49,0.46$ units, which basically consistent with the assumption that constant returns to scale. Reference to relevant literature, the regression results is consistent with other studies: the elastic coefficient of physical capital is lager than human capital. However, the results show a new feature that the elasticity of human capital is relatively high, indicating that human capital plays a growing role in the agricultural economy growth at this period.

Table 2. Model 5 Regression Analysis Results

\begin{tabular}{clccc}
\hline Variable & Coefficient & Std. Error & t-Statistic & Prob. \\
\hline C & 6.327534 & 0.142652 & 44.35655 & 0.0000 \\
K1? & 0.491837 & 0.014703 & 26.65073 & 0.0000 \\
H1? & 0.459361 & 0.015842 & 28.99651 & 0.0000 \\
Fixed Effects (Period) & & & \\
1999--C & 0.055869 & & & \\
2000--C & -0.066871 & & & \\
2001--C & 0.176475 & & & \\
2002--C & -0.055995 & & & \\
2003--C & -0.069044 & & & \\
2004--C & 0.035609 & & & \\
2005--C & -0.013762 & & & \\
2006--C & -0.053886 & & & \\
\hline
\end{tabular}


Table 3. Model 6 Regression Analysis Results

\begin{tabular}{ccccc}
\hline Variable & Coefficient & Std. Error & t-Statistic & Prob. \\
\hline C & 5.693355 & 0.152987 & 37.21457 & 0.0000 \\
K1? & 0.452439 & 0.017724 & 19.88461 & 0.0000 \\
H1? & 0.533188 & 0.023175 & 23.00680 & 0.0000 \\
ICT?(-1) & 0.154849 & 0.023945 & 6.466894 & 0.0000 \\
Fixed Effects (Period) & & & & \\
2000--C & -0.062033 & & & \\
2001--C & 0.175993 & & & \\
2002--C & -0.043696 & & & \\
2003--C & -0.048470 & & & \\
2004--C & 0.059661 & & & \\
2005--C & 0.016271 & & & \\
2006--C & -0.046159 & & & \\
\hline
\end{tabular}

In model 6, the R-square, Adjusted R-square are 0.999871, 0.999866 respectively. F-statistic value is 172870.6 and the Probability of F-statistic value is 0.000000 . Durbin-Watson statistic value is 0.62 . The regression result is interesting. First, ICT application factor past through the $1 \%$ significance hypothesis testing, which means that ICT application has become one of the elements of agricultural economic growth. Second, compared to model 5, the elasticity of physical capital is almost unchanged, while the elasticity of human capital is increased to be larger than the elasticity of physical capital and the sum of them, which is 0.99 , still approximately equal to 1. Third, the elastic coefficients of physical capital, human capital, ICT application factor are $0.45,0.53,0.15$ and the sum of them is 1.13 larger than 1 , indicating that for each additional unit of regional physical capital, human capital, ICT application factor input can stimulate agricultural growth $0.45,0.53,0.15$, which means some increasing returns to scale and ICT application factor increases returns to scale.

Comparing Model 6 and Model 5, on the one hand, we can see that there is a strong consistency of the two models. First, the regression results of the two models are constant in estimates of the elasticity of physical capital and human capital, which the differences between them are comparatively small and the sum of them approximately equal to 1 . Second, the regression results of the two models are constant in estimates of time fixed effects. The meaning of time fixed effects is clearly, apart from the factors including scientific and technology progress, physical capital input and human capital input, it should be natural conditions and the effects of the policies. According to model 6 , the time fixed effects from 2000 to 2006 were $-0.062033,0.175993,-0.043696$, $-0.048470,0.059661,0.016271,-0.046159$, which are reasonable and can be explained by natural conditions and policies. According to the actual agricultural production, 2001 is a favorable weather year in China and this year's agricultural production made a great growth. 2005 is a great time for Chinese farmer, in March 2005, there had been 26 provinces (autonomous regions and municipalities) announced the abolition of agricultural tax, which stimulates agriculture output growth. On the other hand, there 
are differences. First, we know that the constant item in model 5 stands for scientific and technological progress, while the constant item in model 6 stands for scientific and technological progress excluding ICT application factor. From the results, it can be seen that the constant item in model 5 is lager than the constant item in model 6, which is reasonable. Second, the ICT application factor has changed the input-output structure of the agricultural economy. The ICT application factor has become one independent element in the agricultural economic system and increases the contribution of human capital investment to agriculture economic growth. By comparing the results, it can be concluded that both model are reasonable, but model 6 holds more truth.

\section{Discussions}

Through the analysis of agricultural economy growth, we can draw three important conclusions: First, ICT application has become an important factor in agriculture economic growth. Second, ICT application has changed the output elasticity of physical capital and human capital, which reinforces the role of human capital, therefore changed the way of economic growth in agriculture. Third, ICT application has improved the agricultural economic growth rate returns to scale and has become the source of economies scale increment of agriculture. Therefore, In order to, accelerate the development of agricultural economy, the decision-makers should not only to consider the physical capital investment, human capital investment and technological progress in agriculture fields, but attach great importance to promote agricultural and rural informatization development.

Meanwhile, it can be seen that the impact of ICT application on physical capital investment is not obvious. Therefore, in the agricultural informatization construction process, we should pay more attention to develop intelligent equipment, which can directly improve the efficiency of agricultural production, and agricultural informatization construction. There is a need to encourage scientific research institutions, information technology, companies and agricultural enterprises to make efforts to improve the intelligence level of Chinese agricultural production tools and facilities, therefore promote agricultural growth.

\section{References}

1. Porat, M.U.: The Information Economy (9 volumes), Office of Telecommunications Special Publication 77-12, Washington D.C.: U.S. Department of Commerce (1977)

2. Gill, G., Young, K., Pastore, D., Dumagan, J.C., Turk, I.: Economy - Wide and Industry Level Impact of Information Technology (4) (1997)

3. ITU. World telecommunication development report 2006: Measuring ICT for Social and Economic Development (2006)

4. Welfens, P.J.J.: Information \& Communication Technology and capital market perspectives. In: International Economics and Economic Policy, vol. 2(1), Springer, Heidelberg (2005)

5. Zhu, Y.: Informationalization and Its Influence on economy growth. Journal of the China Society for Scientific and Technical Information (5) (1996) 
6. Tao, C.: The Real Analysis of Information Industry of Our Country. Journal of East China JiaoTong University (04) (2001)

7. Zhang, H., Zhang, Q.: Rural informatization impact on Agricultural economic growth. Statistics and Decision (12) (2008)

8. Zhou, X., Zhu, N.: Return to Human Capital in Rural China. Chinese Journal of Population Science (06) (2003) 